\title{
Frontonasal dysplasia associated with tetralogy of Fallot
}

\author{
M M A DE MOOR, R BARUCH, AND D G HUMAN \\ From the Department of Paediatrics and Child Health, Red Cross War Memorial Children's Hospital, \\ Rondebosch 7700, Cape Town, South Africa.
}

SUMMARY Three children with frontonasal dysplasia associated with tetralogy of Fallot are reported. All cases had true hypertelorism and a median nasal groove with absence of the nasal tip. There was no mental deficiency. The facial anomaly is a sporadic, non-genetic interference of the normal development of the face. This is the first report of frontonasal dysplasia associated with a cardiac defect. Multifactorial inheritance of this syndrome is proposed.

Review of published reports has yielded more than 70 cases of frontonasal dysplasia. De Meyer ${ }^{1}$ termed this anomaly median facial cleft syndrome and in a review of 33 cases recognised the variable clinical combinations and severity of the syndrome. There is always true hypertelorism with variations ranging from an absent nasal tip to anterior cranium bifidum occultum and a median cleft palate. Cardiac abnormalities associated with frontonasal dysplasia sequence have not previously been reported. ${ }^{2}{ }^{3} \mathrm{We}$ report three cases of frontonasal dysplasia associated with tetralogy of Fallot.

\section{Case reports}

CASE 1

A white female child (fig 1) presented to the Cardiology Service at six months when a cardiac murmur was noted on routine examination. She was the product of a normal pregnancy and there was no maternal illness or unusual drug intake during this pregnancy. She was delivered by Wrigley's forceps for delay in the second stage of labour. There were no complications from the delivery and normal Apgar scores were noted. There was one sib in the family who was entirely normal and there were no other family members with any facial abnormalities. The patient's development at the time of presentation and at further follow up was normal.

On examination the patient was proportionately under the 3rd centile for height, weight and head

Received for publication 31 July 1985

Revised version accepted for publication 14 October 1985. circumference. She was mildly cyanosed but there was no clubbing. She had a median nasal cleft associated with a broad nasal root. There was ocular hypertelorism and this was confirmed on skull $x$ ray. The interorbital distance was $25 \mathrm{~mm}$ (mean interorbital distance for age $=18 \mathrm{~mm}$; upper limit of normal for age $=23 \mathrm{~mm}^{4}$ ). Her ears and facial appearance were otherwise normal and there were no colobomata, cataracts, or preauricular skin tags.

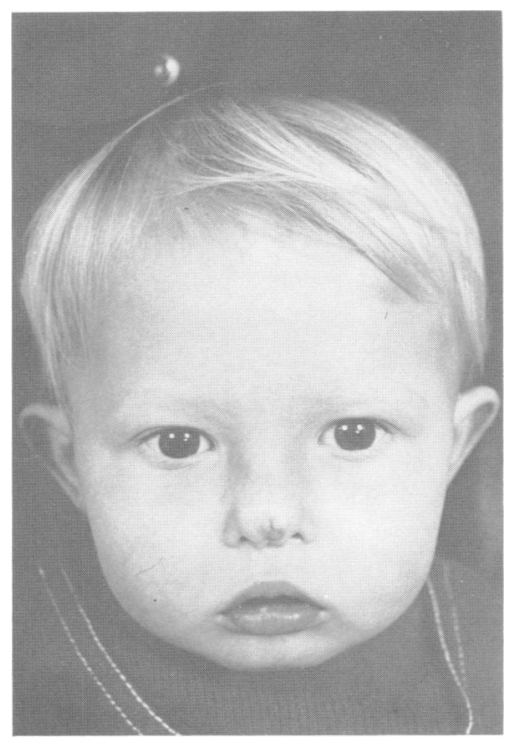

FIG 1 Case 1. 
The cardiovascular abnormalities on clinical examination were consistent with tetralogy of Fallot. The electrocardiogram showed right axis deviation $\left(+135^{\circ}\right)$ and right ventricular hypertrophy. Chest radiography showed a normally sized heart with a pulmonary bay and a right sided aortic arch. The lung vascularity was diminished. At 20 months she developed hypercyanotic spells and cardiac catheterisation was performed which confirmed the diagnosis of tetralogy of Fallot. She was maintained on propranolol to prevent further hypercyanotic spells, although these recurred at 30 months, when corrective surgery was successfully performed.

CASE 2

A coloured male infant (fig 2) presented to the Genetic Clinic at four months for assessment of dysmorphic features. He was the product of a normal delivery and pregnancy in an 18 year old primigravida. There was no family history of facial abnormalities. Developmental milestones were normal.

On examination the weight, height, and head circumference were proportionately below the $3 \mathrm{rd}$ centile. There was absence of the nasal tip with a median nasal groove. He had a widow's peak and ocular hypertelorism (interobital distance on skull $x$ ray $=22 \mathrm{~mm}$, upper limit of normal for age $=21 \mathrm{~mm}^{4}$ ). The left testis was undescended and there were simian creases on both hands.

$\mathrm{He}$ was noted to be moderately cyanosed and

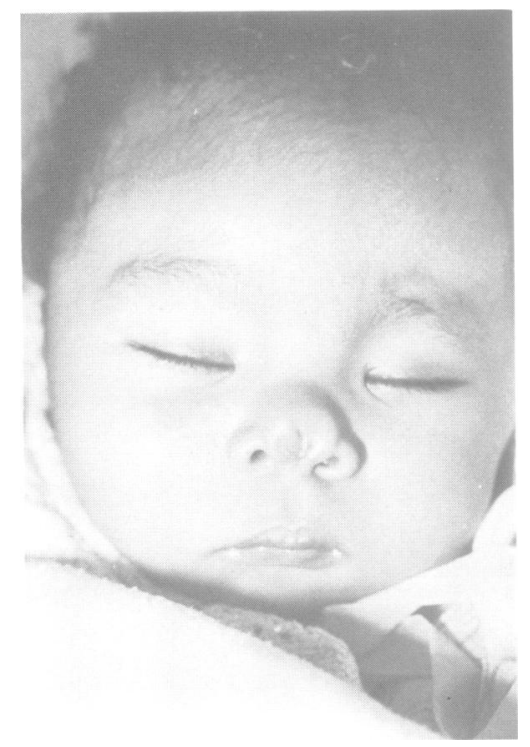

FIG 2 Case 2. clubbed but not in heart failure. There was no clinicat cardiomegaly and on auscultation there was a single second heart sound with a $2 / 6$ ejection systolie murmur. The electrocardiogram showed right axi을 deviation $\left(+120^{\circ}\right)$ and right ventricular hypertrophy? and the chest radiograph showed oligaemic lung fields with a normally sized heart and a left side出 aortic arch.

Cardiac catheterisation was performed at $1 . \vec{P}$ months when the infant developed hypercyanotiz spells despite propranolol therapy. The diagnosis o tetralogy of Fallot was confirmed and a right side承 modified Blalock Taussig shunt was performed.

CASE 3

in

This coloured male (fig 3) was first referred at si years of age following detection of a cardiac murmuro $\mathrm{He}$ was the product of a normal pregnancy and delivery. There was no family history of an $a b_{\bar{T}}$ normal facial appearance and his developmentis milestones were normal. He had recently bee treated for pulmonary tuberculosis.

On examination height, weight, and head circumference were all just below the 3 rd centile for age. Hiso facial appearance showed a broad nasal root with ocular hypertelorism (interorbital distance $=32 \mathrm{~mm}$ upper limit of normal for age $=28 \mathrm{~mm}^{+}$). There was absence of the nasal tip with a shallow median nasi groove. The ears were low set. There were no othed dysmorphic features.

$\mathrm{He}$ was very mildly cyanosed and the clinica

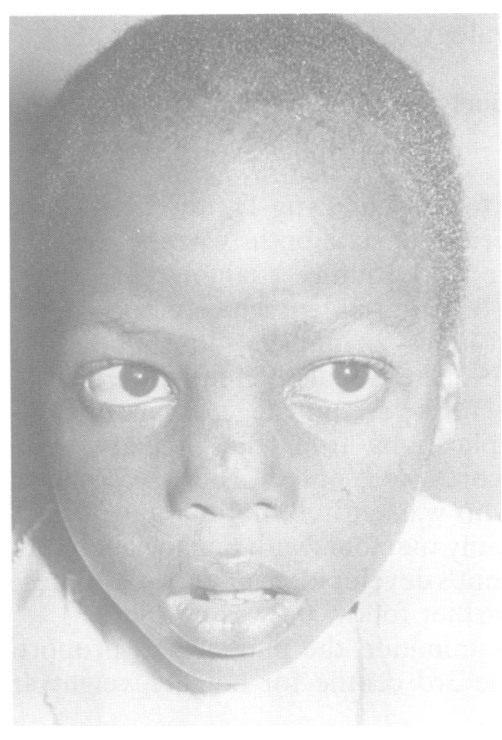

FIG 3 Case 3. 
electrocardiographical, and radiographical findings were those of tetralogy of Fallot. This diagnosis was confirmed at cardiac catheterisation and corrective surgery was performed.

\section{Discussion}

Both De Meyer ${ }^{1}$ and Sedano et al ${ }^{5}$ classified and described frontonasal dysplasia by identifying four basic facies and grading them according to severity. Facies A includes ocular hypertelorism, broad nasal root, and median nasal groove with absence of the nasal tip. Facies B includes ocular hypertelorism, broad nasal root, and deep median facial groove or cleft affecting the nose or both the nose and the upper lip. The palate may also be cleft. Facies C comprises ocular hypertelorism, broad nasal root, and unilateral or bilateral notching of the nasal alae. Facies $\mathrm{D}$ is a combination of facies $\mathrm{B}$ and $\mathrm{C}$. Anterior cranium bifidum occultum can be present in all four types. About $20 \%$ of cases may have mental impairment.

The three cases we have reported all have facies $\mathrm{A}$. Skull $x$ rays on our patients did not reveal anterior cranium bifidum occultum, nor were any of the children mentally deficient. In all three patients growth was below the 3 rd centile. The cardiac defect and cyanosis were not severe enough to warrant this degree of failure to thrive and thus a degree of dwarfism may be part of the underlying syndrome. Abnormalities such as clinodactyly, camptodactyly, cryptorchidism, preauricular skin tags, and brachycephaly have also been associated with the syndrome. These abnormalities are thought to be incidental findings not directly related to the condition and the primary pathology is in the facial development. The hypertelorism in these children confirms the diagnosis of frontonasal dysplasia, rather than the bifid nose recently described as a simple dominant condition. ${ }^{6}$

The aetiology of frontonasal dysplasia is unknown. Most cases are sporadic although autosomal dominant inheritance has been suggested in some families. ${ }^{7}$ Multifactorial transmission has been proposed and tetralogy of Fallot, like most congenital heart defects, is also presumed to result from multifactorial inheritance. Between four and six weeks of embryogenesis some environmental factor causes an anterior displacement of the conus septum resulting in infundibular stenosis and an inability to close the interventricular septum. The development of the mid-portion of the face also occurs at this stage and so we propose that frontonasal dysplasia and tetralogy of Fallot have a multifactorial mode of inheritance and that both may be initiated by a similar environmental factor.

The finding of three cases within one hospital referral population suggests that this association may not be very uncommon, and thus children with obvious mid-facial defects should be screened carefully for cardiac defects. A single isolated environmental factor appears unlikely as these three cases, at the time of embryogenesis, were widely separated in time and place.

We wish to thank the parents of these children for permission to publish the photographs, and Dr J G L Strauss, Medical Superintendent, for permission to publish this report.

\section{References \\ ${ }^{1}$ De Meyer W. The median cleft face syndrome. Differential diagnosis of cranium bifidum occultum, hypertelorism and median cleft nose lip and palate. Neurology (Minneap) 1967;17: 961-71. \\ ${ }^{2}$ Smith DW. Recognizable patterns of human malformation. Genetic, embryologic and clinical aspects. 3rd ed. Philadelphia: Saunders, 1982:177-8. \\ 3 Noonan JA. In: Engel MA, ed. Syndromes associated with cardiac defects in pediatric cardiovascular disease. Philadelphia: Davis. 1981:97-116. \\ ${ }^{4}$ Currarino G, Silverman FN. Orbital hypertelorism, arhinen- cephaly and trigonocephaly. Radiology 1960;74:206-16. \\ 5 Sedano HO. Cohen MM, Jirasek DMD, Gorlin RJ. Frontonasal dysplasia. J Pediatr 1970;76:906-13. \\ 6 Anyane-Yeboa K, Raifman MA, Berant M, Frogel MP, Travers H. Dominant inheritance of bifid nose. Am J Med Genet 184:17:561-3. \\ ${ }^{7}$ Goodman RM, Gorlin RJ. The malformed infant and child. New York: Oxford University Press, 1983:262-3.}

Correspondence and requests for reprints to $\mathrm{Dr}$ M M A De Moor, Department of Paediatrics and Child Health, Red Cross War Memorial Children's Hospital, Klipfontein Road, Rondebosch 7700, Cape Town, Republic of South Africa. 